\title{
Pyritization of trace metals in estuarine sediments and the controlling factors: a case in Jiaojiang Estuary of Zhejiang Province, China
}

\author{
Siyuan Ye $\cdot$ Edward A. Laws $\cdot$ Qiang Wu • \\ Shaojun Zhong $\cdot$ Xigui Ding $\cdot$ Guangming Zhao $\cdot$ \\ Shaojun Gong
}

Received: 2 February 2009/ Accepted: 8 December 2009/Published online: 13 January 2010

(C) The Author(s) 2010. This article is published with open access at Springerlink.com

\begin{abstract}
Three undisturbed sediment samples were collected from the intertidal zone of the Jiaojiang Estuary of Zhejiang Province, China. The sediments were found to contain remarkably low concentrations of organic carbon $(<0.6 \%)$ and acid volatile sulfide (AVS) $\left(<30 \mu \mathrm{mol} \mathrm{g}^{-1}\right)$. The availability of these two substrates likely constrained sulfate reduction and pyritization of several trace metals, respectively. This was especially true at one station where AVS concentrations in the upper $20 \mathrm{~cm}$ averaged less than $0.05 \mu \mathrm{mol} \mathrm{g}^{-1}$. Although the depth dependence of the degree of trace metal pyritization was generally consistent with expectations based on redox conditions, depth profiles of reactive-metal and pyrite-metal concentrations in several cases revealed more complex behavior and a positive correlation between reactive-metal concentrations and pore water metal concentrations.
\end{abstract}

S. Ye $(\bowtie) \cdot S$. Zhong $\cdot$ X. Ding $\cdot$ G. Zhao $\cdot$ S. Gong

Key Laboratory of Marine Hydrocarbon Resources and

Environmental Geology, Ministry of Land and Resources,

62 Fuzhou Road, Qingdao, P.O. Box 266071,

People's Republic of China

e-mail: siyuanye@hotmail.com

S. Ye $\cdot$ S. Zhong $\cdot$ X. Ding $\cdot$ G. Zhao $\cdot$ S. Gong

Qingdao Institute of Marine Geology,

62 Fuzhou Road, Qingdao, P.O. Box 266071,

People's Republic of China

E. A. Laws $(\bowtie)$

Louisiana State University, Baton Rouge, LA 70803-4110, USA

e-mail: edlaws@1su.edu

Q. $\mathrm{Wu}$

China University of Mining and Technology,

Beijing, People's Republic of China

e-mail:wuq@cumtb.edu.cn
Keywords Estuarine sediments - Trace metals .

Reactive fraction - Pyrite fraction .

Jiaojiang Estuary of Zhejiang of China

\section{Introduction}

River-borne pollutants, including especially trace metals, tend to accumulate in estuaries, where their potentially damaging effects are a concern to environmental geochemists. Of current interest with respect to the bioavailability of these metals are their relationships to pyrite and acid volatile sulfide (AVS), and the mechanism(s) of their coprecipitation with pyrite (Edenborn et al. 1986; Huerta-Diaz and Morse 1992; Peterson and Carpenter 1986). Previous studies have shown that both thermodynamic considerations and kinetic constraints impact the association of these metals with pyrite (Calvert and Morris 1977; Contreras et al. 1978; Davies-Colley et al. 1985; Elderfield et al. 1979; Fleischer 1955; Framson and Leckie 1978; Morse and Luther 1999; Shea and Helz 1988), and the understanding of trace metal bioavailability that has emerged from this previous work has had important environmental, biological and geochemical implications.

Of the world's population of 6.7 billion China currently accounts for $\sim 20 \%$. Almost $60 \%$ of Chinese citizens live in 12 coastal provinces, along the Yangtze River valley, and in the coastal municipalities of Shanghai and Tianjin (Hinrichsen 1999). This large coastal population is closely associated with serious pollution of China's coastal waters as a result of riverine export of agricultural chemicals from coastal catchments and discharges of domestic and industrial wastes (Cao and Wong 2007). With few exceptions (Ye et al. 2006a, b; Zhang et al. 2003) there are remarkably 
few reports on the distribution and speciation of trace metals in the sediments of major polluted Chinese estuaries and even fewer on the behavior and bioavailability of trace metals during early diagenesis. Lacking such information makes it impossible to determine the bioavailable and potentially bioavailable fractions of trace metals in these sediments and to predict, in particular, the bioavailability of toxic elements. Trace metal speciation directly impacts metal transference across the sediment-water interface, i.e., trace metals can emerge from their pyritic phase in anoxic sediments and diffuse into the overlying water, and trace metals in bottom waters can move into sediments through absorption and coprecipitation (incorporation into pyrite). Therefore, pyritization and reverse pyritization of trace metals are important processes controlling bioavailability. Morse (1994), for example, has shown that more than $20 \%$ of sedimentary pyrite can be rapidly oxidized into a reactive phase and become bioavailable in oxic seawater. Hence, when seafloor sediments are resuspended and/or redox conditions become more oxidizing, metals previously sequestered in unreactive sedimentary phases can become bioavailable.

The total amount of pyrite formed in a marine environment is strongly dependent on the environment's redox characteristics (Berner 1970, 1980). It is therefore expected that the proportion of a given trace metal incorporated into the pyrite phase will depend on these same redox characteristics. During the present study, three undisturbed samples were collected from Jiaojiang Estuary in the Zhejiang Province of China to determine the pyritization of potentially toxic trace metals $(\mathrm{As}, \mathrm{Cd}, \mathrm{Cr}, \mathrm{Cu}, \mathrm{Hg}, \mathrm{Mn}, \mathrm{Ni}, \mathrm{Pb}$, and $\mathrm{Zn}$ ) in the sediments, to analyze the distribution of the pyritic and reactive (bioavailable) fractions of these metals in the sediment profile, and to examine the relationship between environmental conditions such as AVS and organic matter content and trace metal transference into the pyritic phase.

\section{Description of the study area}

Three core samples (TZ01, TZ02, and TZ03) were collected from Jiaojiang Estuary in Taizhou Bay, Zhejiang Province. The Zhejiang coast borders the East China Sea and lies in the middle of China's coastal zone; it is flanked by Shanghai City to the north and Fujian Province to the south. Taizhou Bay, in the central part of the Zhejiang coast, is seriously impacted by discharges of chemical pollutants, mainly from the Jiaojiang River (Fig. 1). Sediments in the bay progress from clayey silt to silt in a southerly direction from Jiaojiang Estuary. The tidal range is $0.8-6.3 \mathrm{~m}$ with an average of $4 \mathrm{~m}$.

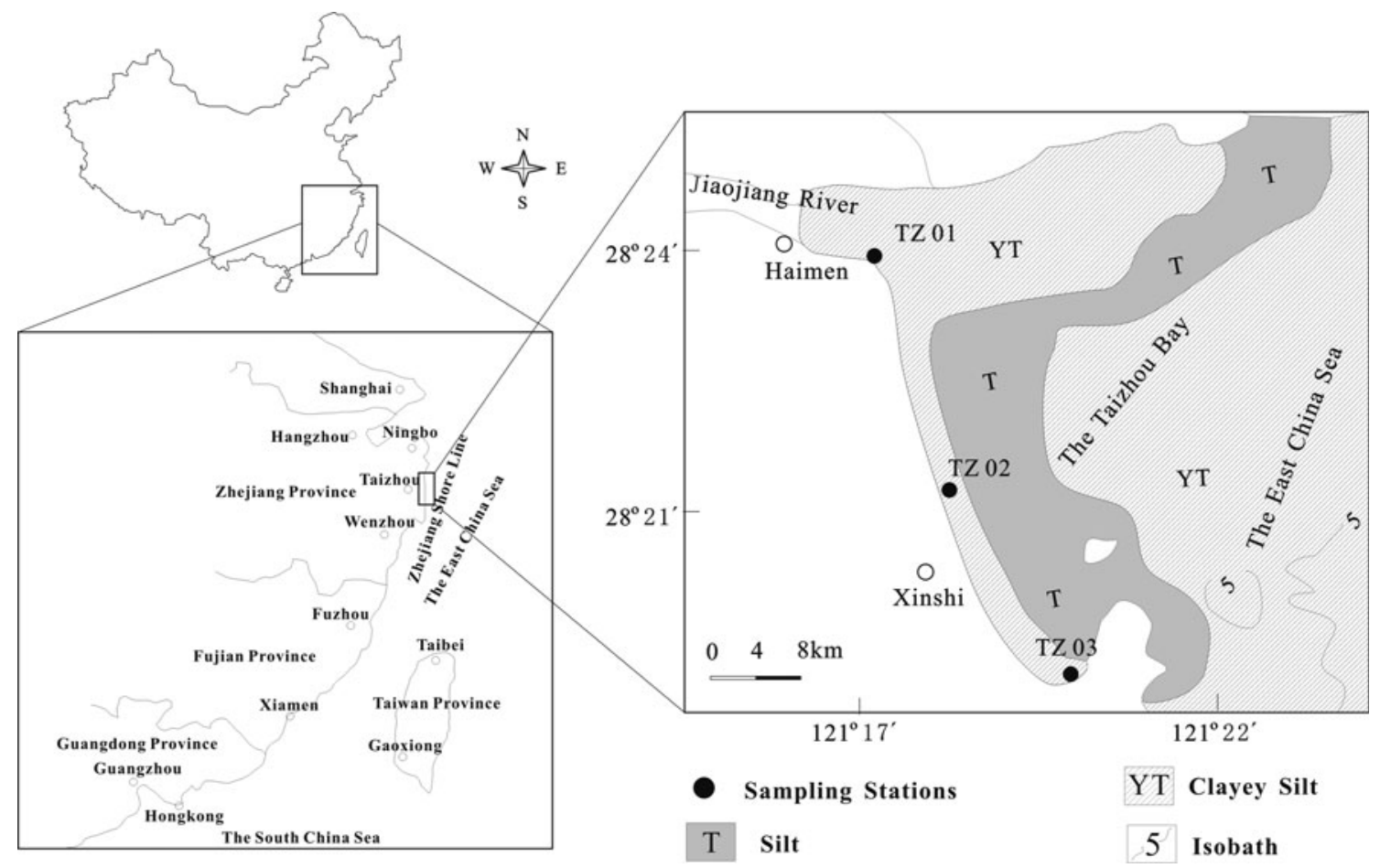

Fig. 1 Sampling locations in Jiaojiang Estuary 


\section{Materials and methods}

Cores TZ01, TZ02 and TZ03 were obtained by inserting a seven-centimeter diameter PVC pipe into the sediments during the low ebb tide. The pipe was capped, lifted vertically out of the water, the bottom sealed with a lid, and surficial water pumped out. The cores were then sealed and placed in a vertical position in a freezer $\left(-20^{\circ} \mathrm{C}\right)$. Cores TZ01, TZ02, and TZ03 were 30, 38, and $38 \mathrm{~cm}$ long, respectively. In the laboratory, they were subsampled at two-centimeter intervals under a nitrogen atmosphere. After freeze drying, two-gram subsamples were taken from each 2-cm section for speciation analysis. The subsamples were digested following the procedures described by $\mathrm{Hu}-$ erta-Diaz and Morse (1990) as refined by Lord (1982) to separate the following three operationally defined fractions (1) reactive fraction: digested while shaking in $1 \mathrm{M} \mathrm{HCl}$ for $16 \mathrm{~h}$. This fraction includes crystalline, amorphous iron and manganese oxyhydroxides, carbonates, and hydrous aluminosilicates. The metallic component of the reactive fraction includes exchangeable metals, metallic sulfides (not including pyrite), and carbonate-related metals. (2) Silicate fraction: digested while shaking in $10 \mathrm{M} \mathrm{HF}$ for $16 \mathrm{~h}$. Five grams of boric acid are then used to re-dissolve precipitated fluorides. This fraction is comprised of clay minerals. (3) Pyrite fraction: obtained by using concentrated $\mathrm{HNO}_{3}$ to digest solid residuals from step (2) for $2 \mathrm{~h}$. This fraction consists of pyrite-associated trace metals.

Since trace metals associated with the above silicate fraction do not take part in element transference during early diagenesis and are thus not considered to be bioavailable, chemical testing and analyses were not done on them. Hence the sum of the metal $(\mathrm{Me})$ concentrations in the reactive and pyrite metal fractions (reactive-Me + pyrite-Me) was considered to be bioavailable. Arsenic and $\mathrm{Hg}$ were measured using atomic fluorescence spectrometry (AFS-230) according to state standard (GB17378-1998); the analytical precision was better than $\pm 5 \%$. Cd and $\mathrm{Cr}$ were assayed following DZ/T0223-2001 using an ExCell inductively coupled plasma (ICP). $\mathrm{Cu}, \mathrm{Pb}, \mathrm{Zn}, \mathrm{Ni}, \mathrm{Fe}$, and $\mathrm{Mn}$ were analyzed using an IRIS ICP (JY/T015-1996); the analytical precision was better than $\pm 5 \%$.

AVS data were obtained using Hsieh's cold diffusion method (Hsieh et al. 2002; Hsieh and Shieh 1997) as follows: about $10 \mathrm{~g}$ of wet sediment were weighed and transferred to a 250-ml flask; $2 \mathrm{ml} 1 \mathrm{M}$ ascorbic acid solution were added; a plastic vial containing $15 \mathrm{ml} \mathrm{(3 \% )}$ alkaline $\mathrm{Zn}$ solution was placed in the flask; the flask was purged with pure $\mathrm{N}_{2}$ gas while injecting $15 \mathrm{ml} 8 \mathrm{M} \mathrm{HCl}$ solution to initiate the reaction; the reaction was allowed to proceed for $18 \mathrm{~h}$ at room temperature; the plastic vial was then removed, the cover screwed tightly, and the vial stored in a dark, cool place. Sulfides in the absorbed liquid were measured using iodine as an oxidant (Hsieh and Shieh 1997).

Samples for organic carbon analysis were initially ground, acidified to remove inorganic carbon, and freeze dried. The samples were then further ground ( $<100 \mathrm{mesh})$ and $\sim 10 \mathrm{mg}$ weighed for final analysis. Carbon contents were determined using a FlashEA-112 elemental analyzer (Thermo Company) with an analytical precision of $\pm 1 \%$. Pore water samples were obtained by centrifuging aliquots of sediment and were analyzed for trace metals as described above.

Statistical tests were carried out using analysis of variance (ANOVA), Kruskal-Wallis (KW), and runs tests (Sokal and Rohlf 1981). To examine the data for (1) systematic differences in the degree of trace metal pyritization (DTMP) between stations and (2) patterns of DTMP variation with depth, the data were first normalized to filter out noise from depth variations in the former case and interstation differences in the latter case. Specifically, to look for differences between stations, the metal DTMP values were normalized at each depth by subtracting the mean DTMP (averaged over stations) at that depth and dividing the difference by the standard deviation of the DTMP at that depth. The DTMP values so normalized had the same mean (zero) and standard deviation (one) at each depth. Likewise, to look for variations with depth, the DTMP values were normalized at each station by subtracting the meant DTMP (averaged over all depths to $30 \mathrm{~cm}$ ) and dividing by the corresponding standard deviation. The DTMP values so normalized had the same mean (zero) and standard deviation (one) at each station.

\section{Results}

Vertical distributions of organic carbon (Org-C) and AVS are shown in Fig. 2. To compare results between stations, statistical analyses were carried out on the data from the upper $30 \mathrm{~cm}$ of each core. Mean percentages of organic carbon in the upper $30 \mathrm{~cm}$ were $0.40 \pm 0.02,0.53 \pm 0.01$, and $0.56 \pm 0.01$ at stations TZ01, TZ02, and TZ03, respectively, where the error bounds are the standard deviations of the mean values. A Kruskal-Wallis (KW) test revealed a highly significant $\left(p=1.2 \times 10^{-6}\right)$ difference in the percentages of organic carbon between stations, with TZ01 clearly having the smallest percentage. The difference in percent organic carbon between stations TZ02 and TZ03 was much smaller but nevertheless significant at $p=0.05$ based on a paired $t$ test. There was no systematic variation of Org-C concentrations with depth at any of the stations.

Mean AVS concentrations in the upper $30 \mathrm{~cm}$ were $12.6 \pm 2.2, \quad 0.37 \pm 0.17, \quad$ and $\quad 6.1 \pm 2.5 \mu \mathrm{mol} \mathrm{g}^{-1}$ at 
Fig. 2 Variations of sedimentary organic carbon and AVS concentrations with depth at the three sampling stations

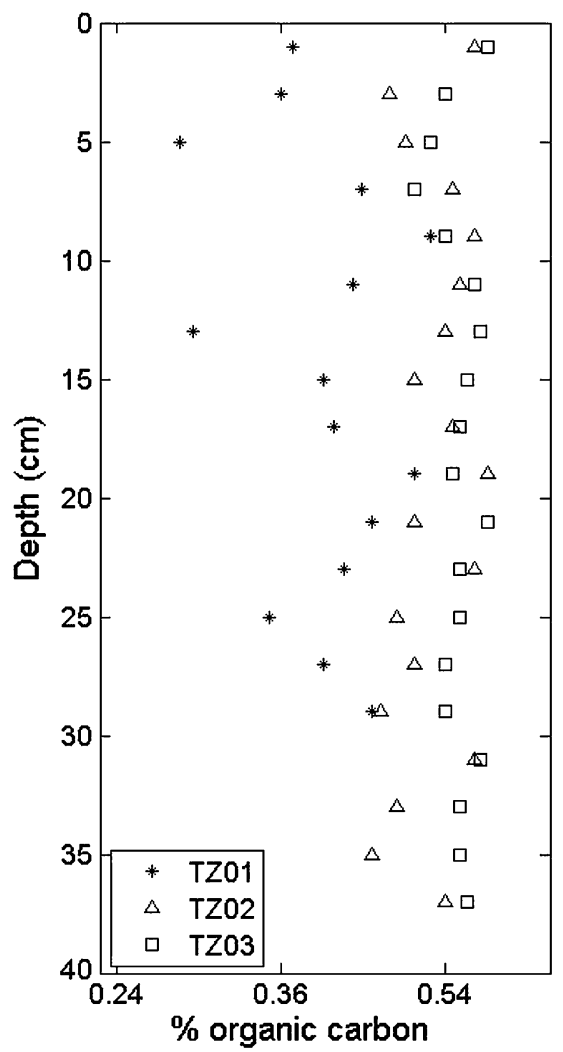

stations TZ01, TZ02, and TZ03, respectively. A KW test again revealed a highly significant difference between stations $\left(p=9.8 \times 10^{-7}\right)$, with station TZ01 clearly having the highest concentrations. The AVS concentrations at station TZ03 exceeded the AVS concentrations at station TZ02 in 17 of 19 paired comparisons (in this case including all samples to a depth of $38 \mathrm{~cm}$ ), a highly improbable result by random chance $\left(p=3.6 \times 10^{-4}\right)$. AVS concentrations at station TZ02 increased dramatically below a depth of $\sim 20 \mathrm{~cm}$. There was no systematic variation of AVS with depth at the other two stations.

The sum of reactive and pyretic metal concentrations averaged over all depths and stations are summarized in Table 1, and average percentages of each metal associated with the pyrite fraction are summarized in Table 2. The pattern of metal concentrations is qualitatively consistent with earlier reports (e.g., Otero et al. 2003) in which Fe and $\mathrm{Mn}$ are present in the highest concentrations, $\mathrm{Zn}, \mathrm{Cu}$, and $\mathrm{Ni}$ concentrations are roughly two orders of magnitude lower, and $\mathrm{Pb}$ and $\mathrm{Cr}$ concentrations are lower by an additional factor of $\sim 5$. Three of the metals of greatest environmental concern, $\mathrm{As}, \mathrm{Cd}$, and $\mathrm{Hg}$, were present at even lower concentrations. The percentages of metals in the pyrite fraction varied widely (Table 2 ), from $\sim 1 \%$ for $\mathrm{Mn}$ to greater than $90 \%$ for $\mathrm{Hg}$. Of the more toxic metals, more than $50 \%$ of $\mathrm{As}, \mathrm{Cd}$, and $\mathrm{Hg}$ were found in the pyrite fraction, but only $8 \%$ of $\mathrm{Pb}$ was pyritized.
Table 1 Median reactive + pyretic metal concentrations and associated $95 \%$ confidence limits for all stations and depths in Jianjiang Estuary

\begin{tabular}{lll}
\hline Metal & $\begin{array}{l}\text { Median value } \\
\text { (all stations and depths) }\end{array}$ & $\begin{array}{l}95 \% \text { confidence } \\
\text { limits to median }\end{array}$ \\
\hline $\mathrm{Fe}$ & $1.79 \times 10^{5}$ & $(1.63-1.84) \times 10^{5}$ \\
$\mathrm{As}$ & 49 & $45-52$ \\
$\mathrm{Cd}$ & 10 & $9-11$ \\
$\mathrm{Cr}$ & 94 & $84-122$ \\
$\mathrm{Cu}$ & $4.0 \times 10^{2}$ & $(3.5-4.2) \times 10^{2}$ \\
$\mathrm{Hg}$ & 0.34 & $0.32-0.36$ \\
$\mathrm{Mn}$ & $1.4 \times 10^{4}$ & $(1.3-1.5) \times 10^{4}$ \\
$\mathrm{Ni}$ & $2.1 \times 10^{2}$ & $(1.9-2.2) \times 10^{2}$ \\
$\mathrm{~Pb}$ & $1.1 \times 10^{2}$ & $(1.0-1.1) \times 10^{2}$ \\
$\mathrm{Zn}$ & $9.4 \times 10^{2}$ & $(8.9-10.0) \times 10^{2}$ \\
\hline $\mathrm{All}$ &
\end{tabular}

All values are nanomoles per gram sediment

The approach used to detect differences in DTMP between stations and depths is illustrated in the case of $\mathrm{Fe}$ in Fig. 3. The upper left and right panels show the average degree of pyritization (DOP) and normalized DOP values at each station, respectively. Based on an analysis of variance (ANOVA), there is no difference $(p=0.17)$ in the DOP between these stations. This conclusion is true for both the untransformed data and normalized data. The bottom left and right panels show the average DOP and 
Table 2 Median percentages of metals in pyrite fraction and associated $95 \%$ confidence limits for all stations and depths in Jianjiang Estuary

\begin{tabular}{llc}
\hline Metal & $\begin{array}{l}\text { Median value } \\
\text { (all stations and depths) }\end{array}$ & $\begin{array}{l}95 \% \text { confidence } \\
\text { limits to median }\end{array}$ \\
\hline $\mathrm{Fe}$ & 11 & $8-19$ \\
$\mathrm{As}$ & 51 & $44-57$ \\
$\mathrm{Cd}$ & 53 & $50-58$ \\
$\mathrm{Cr}$ & 40 & $24-45$ \\
$\mathrm{Cu}$ & 18 & $16-19$ \\
$\mathrm{Hg}$ & 96 & $86-98$ \\
$\mathrm{Mn}$ & 1.4 & $0.9-1.9$ \\
$\mathrm{Ni}$ & 15 & $10-18$ \\
$\mathrm{~Pb}$ & 8 & $6-9$ \\
$\mathrm{Zn}$ & 27 & $23-32$ \\
\hline
\end{tabular}

normalized DOP values as a function of depth. Based on a runs test, the data show a systematic pattern of variation with depth $(p<0.02)$. At depths less than $\sim 10 \mathrm{~cm}$ the DOP values are relatively low, at depths between $\sim 10$ and $20 \mathrm{~cm}$ the DOP values are relatively high, at depths between $\sim 20$ and $25 \mathrm{~cm}$ the DOP values are relatively low, and at greater depths they are relatively high. This pattern is apparent regardless of whether the data are untransformed (lower left) or normalized (lower right).

The conclusions concerning inter-station differences and depth variations in this case are independent of whether the data are untransformed or normalized, and this was the case for most of the metals. However, there were a few cases where normalizing the data successfully filtered out noise that obscured differences or patterns in the untransformed data. For this reason, normalized data were examined for evidence of inter-station differences and depth variations in the remaining data sets.

Figure 4 shows the six cases where inter-station differences in DTMP were judged to be significant by ANOVA. In the case of $\mathrm{Ni}$ the differences were significant at only $p=0.06$. In the other five cases the type I error rate was less than 0.01. In four of the six cases the DTMP was lowest at station TZ02, and in four of six cases the DTMP was highest at station TZ01. This pattern is consistent with the concentrations of AVS at these stations (Fig. 2). There was no significant inter-station difference in DTMP for Mn $(p=0.27), \mathrm{Cr}(p=0.19)$ and $\mathrm{Pb}(p=0.09)$.

Runs tests revealed a significant pattern of depth variation for six of the metals (Fig. 5) in addition to Fe. The pattern of depth variation was similar for all six metals. DTMP values were consistently low near the surface. At depths greater than $\sim 10 \mathrm{~cm}$ DTMP values increased. In some cases they remained high at all depths greater than $\sim 10 \mathrm{~cm}$; in other cases there was a local minimum in the vicinity of $\sim 20-25 \mathrm{~cm}$, with increasing values at greater depths. There was no significant pattern of depth variation in the DTMP of $\mathrm{Cd}, \mathrm{Ni}$, and $\mathrm{Zn}$.

Four pore water metal concentrations showed systematic variations with depth (Fig. 6). Fe and $\mathrm{Cr}$ concentrations were positively correlated with depth $(p<0.05)$, $\mathrm{Cu}$ concentrations were negatively correlated with depth $(p<0.05)$, and Mn concentrations peaked at $\sim 10 \mathrm{~cm}$ and declined at deeper and shallower depths (runs test, $p<0.05)$.

\section{Discussion}

The incorporation of metals into pyrite is influenced by a number of factors including (1) the availability of sulfate and the activity of sulfate-reducing bacteria (Fang et al. 2002), (2) the concentration of reactive iron, (3) the availability of organic carbon, (4) thermodynamics, and (5) kinetics (Morse and Luther 1999). An important caveat to bear in mind is that the pyrite fraction operationally defined by the chemical separation procedure used in this study may include metals not strictly bound in pyrite (Morse and Luther 1999; Otero et al. 2003).

The Org-C concentrations reported in this study (Fig. 2) are low and would be expected to limit the rate of sulfate reduction (Westrich and Berner 1984). This fact has probably constrained rates of pyrite formation and associated AVS concentrations (Morse and Rickard 2004). This is particularly true at station TZ02, where the AVS concentrations in the upper $18 \mathrm{~cm}$ were less than $0.06 \%$. This likely explains the low DTMPs for $\mathrm{As}, \mathrm{Cu}, \mathrm{Hg}$, and $\mathrm{Ni}$ at this station (Fig. 4). The pattern of low DOP and DTMP in the first few centimeters of sediment (Figs. 3, 5) is consistent with the impact of bioturbation and physical turbulence on redox conditions in surficial sediments.

Most of the features of the DTMP results are consistent with thermodynamic/kinetic arguments invoked by Morse and Luther (1999):

- The DTMP of $\mathrm{Hg}$ is high (96\%). This result may be an artifact of the tendency of $\mathrm{Hg}$ in sulfidic sediments to form an $\mathrm{HgS}$ phase that extracts with the pyrite fraction. Kinetic arguments suggest that $\mathrm{Hg}$ should form a mineral phase prior to the formation of $\mathrm{FeS}$ and $\mathrm{FeS}_{2}$. Operationally, however, it is impossible to tell whether $\mathrm{Hg}$ is present as a distinct sulfide mineral or as a co-precipitate with pyrite (Morse and Luther 1999).

- The DTMP of Mn is low (1.4\%). Rapid kinetics results in the incorporation of much of the Mn(II) in anoxic sediments into a carbonate fraction prior to sulfate reduction. This results in a very low DTMP for Mn, even when the DOP is high (Otero et al. 2003). 
Fig. 3 Untransformed and normalized DOPs versus station (upper panels) and versus depth (lower panels). Error bars are standard deviations of mean values. Runs tests were based on sequences of values above or below dashed line
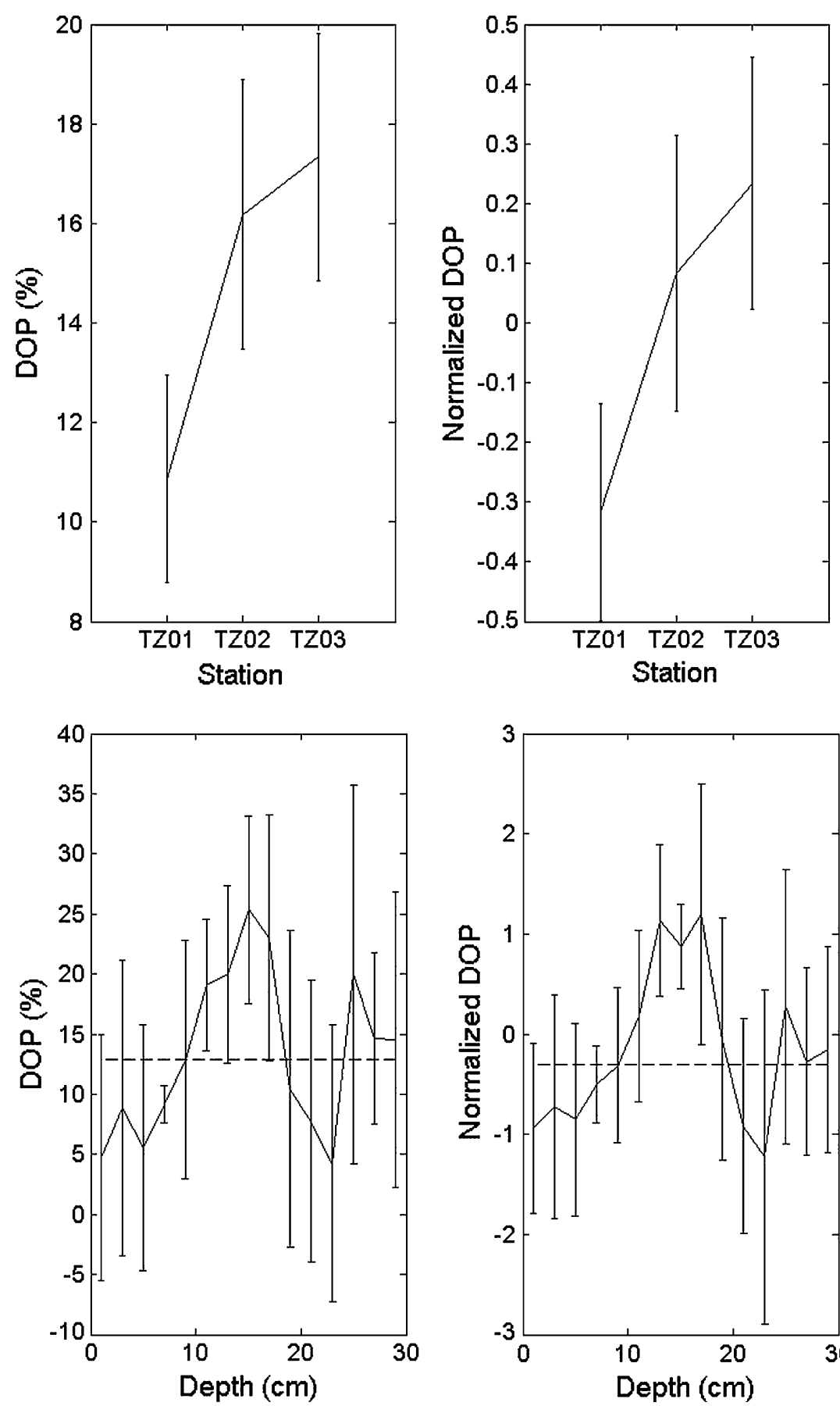

- The DTMP for $\mathrm{Pb}$ is low (8\%). Kinetic arguments suggest that $\mathrm{Pb}$ will form a sulfide mineral faster than $\mathrm{Fe}$ and hence be unavailable for incorporation into $\mathrm{FeS}$ and $\mathrm{FeS}_{2}$. This logic is consistent with the fact that most lead DTMP values are less than 30\% (Huerta-Diaz and Morse 1990; Huerta-Diaz and Morse 1992) but is not infallible. Otero et al. (2003) found lead DTMPs to be $\sim 70 \%$ in the sediments of the Guaymas Basin.

- The DTMP for $\mathrm{Cu}(18 \%)$ is somewhat higher than the DOP $(11 \%)$. This result is consistent with thermodynamic arguments, although Morse and Luther (1999) argue that $\mathrm{Cu}$ should form a sulfide mineral phase faster than $\mathrm{Fe}$, and its DTMP should therefore be controlled by kinetics rather than thermodynamics. They go onto point out, however, that understanding the behavior of $\mathrm{Cu}$ in anoxic sediments is confounded by the fact that $\mathrm{Cu}$ commonly exists in both the +2 and +1 oxidation states and may be found in a number of copper sulfide and iron-sulfide phases. Reported copper DTMP values range from almost zero to more than 
Fig. 4 Normalized DTMPs of metals evidencing significant differences between stations. Error bars are standard deviations of mean values
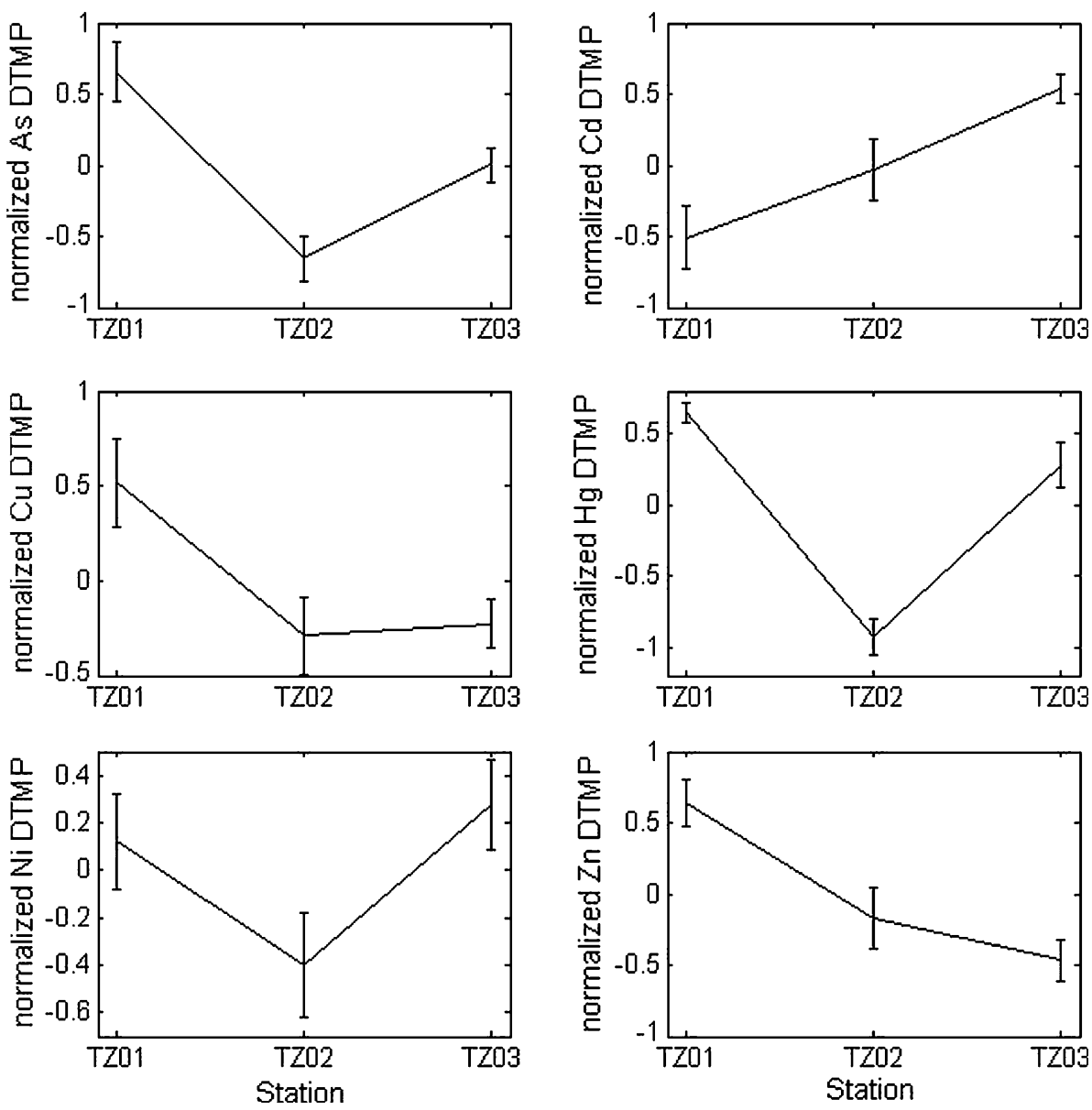

50\% when the DOP is less than 20\% (Huerta-Diaz and Morse 1992).

- The DTMP for As is high (51\%). Morse and Luther (1999) suggest that As is likely to co-precipitate with sedimentary pyrite, for example as arsenopyrite. Because arsenic must be reduced from $\mathrm{As}(\mathrm{V})$ to $\mathrm{As}(\mathrm{III})$ before being incorporated into sulfide minerals, its DTMP is sensitive to complex redox pathways (Morse and Luther 1999), and reported DTMPs for As range from 0 to $100 \%$ at DOPs less than 20\% (Huerta-Diaz and Morse 1992).

- The DTMP for Ni (15\%) is comparable to the DOP $(11 \%)$. This result is consistent with thermodynamics and the fact that $\mathrm{Ni}^{2+}$ is less reactive to water substitution than $\mathrm{Fe}^{2+}$.

- The DTMP for $\mathrm{Cr}$ is $40 \%$. This result is consistent with the fact that $\mathrm{Cr}^{3+}$ is kinetically inert to substitution reactions and has one of the slowest rate constants for water exchange (Burgess 1999), substantially slower than the corresponding rate constant for $\mathrm{Fe}^{2+}$. Therefore it would not be expected to combine with sulfur prior to the formation of $\mathrm{FeS}$ and $\mathrm{FeS}_{2}$. However, Morse and Luther (1999) note that $\mathrm{Cr}^{3+}$ is also kinetically inert to reaction with $\mathrm{S}^{2-}$ and "is not incorporated into pyrite" (p. 3378). Otero et al. (2003) point out that the only $\mathrm{Cr}$ sulfides identified to date have been found in the nuclei of meteorites. Reported DTMPs for $\mathrm{Cr}$ are typically less than $20 \%$, but, consistent with the results of this study, Huerta-Diaz and Morse (1992) have reported values of more than $40 \%$ in sediments in which DOPs are less than $20 \%$. Otero et al. (2003) were surprised to find chromium DTMPs of $100 \%$ in Guaymas Basin sediments and suggested (p. 1160) that the Cr "was probably present in pyrite due to isomorphic substitution of Fe."

Seemingly inconsistent with the thermodynamic/kinetic arguments invoked by Morse and Luther (1999) are the following results of this study:

- The average DTMP of $\mathrm{Zn}$ was $27 \%$. Previous work has generally shown the DTMP of $\mathrm{Zn}$ to be less than 20\% (Huerta-Diaz and Morse 1992; Otero et al. 2000), the explanation presumably being the fact that the water exchange rate is ten times higher for $\mathrm{Zn}^{2+}$ than $\mathrm{Fe}^{2+}$ (Burgess 1999). However, Otero et al. (2003) report a DTMP for Zn of $100 \%$ in Guaymas Basin sediments and speculate (p. 1160) "Zn precipitates along with $\mathrm{Fe}$ to form mixed sulfides that are not soluble in $\mathrm{HCl}$." Of 
Fig. 5 Normalized DTMPs of metals evidencing systematic variations of DTMP with depth. Runs tests were based on sequences of values above or below dashed lines. Error bars are standard deviations of mean values

Fig. 6 Pore water concentrations of metals whose concentrations evidence

systematic variation with depth. Error bars are standard deviations of mean values
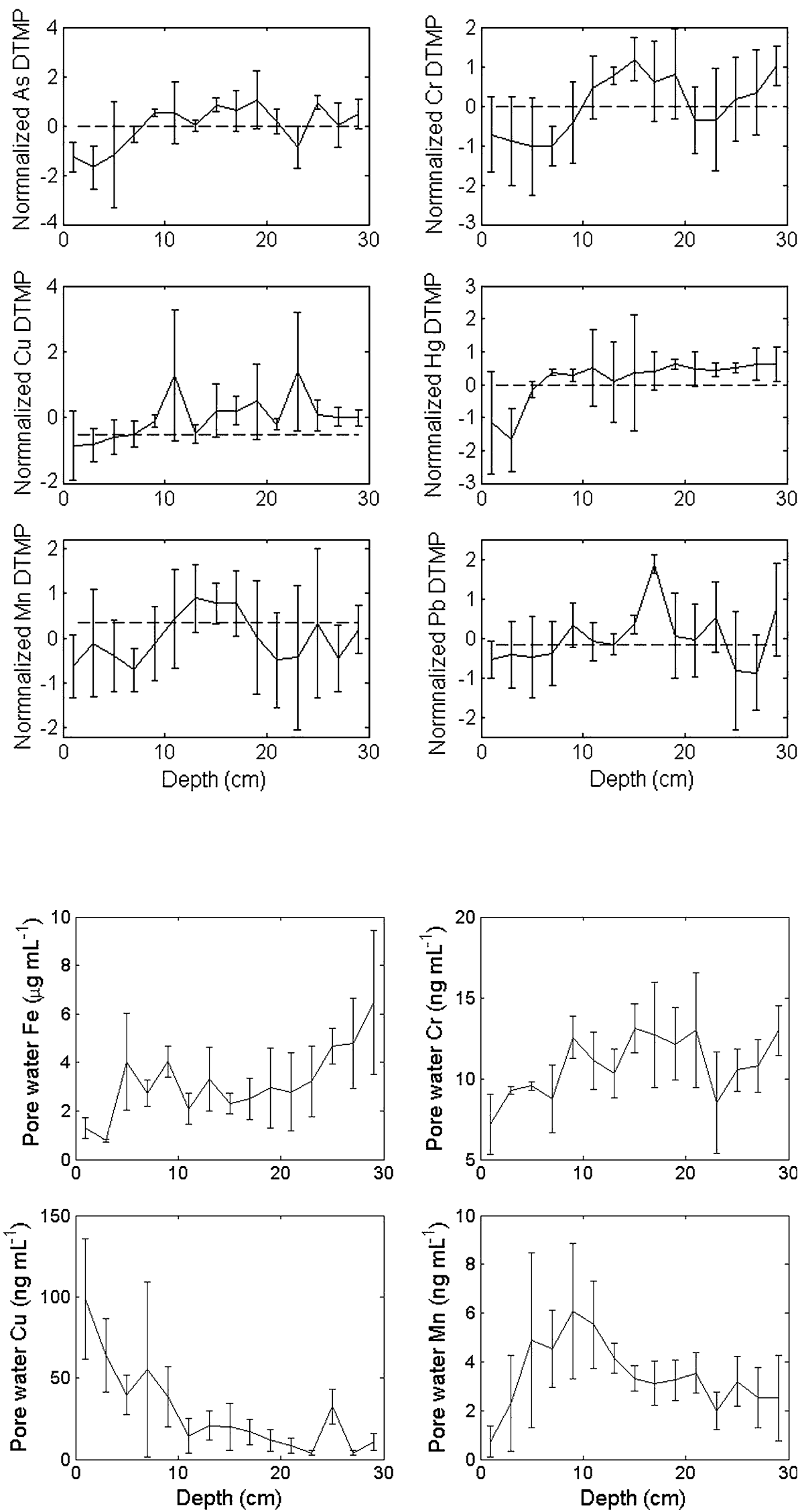
note in the case of the Jiaojiang Estuary is the remarkably high $\mathrm{Zn}$ concentrations in the sediments $\left(\sim 9.4 \times 10^{2} \mathrm{nmol} \mathrm{g}^{-1}\right)$, roughly five times higher than the $\mathrm{Zn}$ concentrations reported by Otero et al. (2003).

- The average Cd DTMP was 53\%. All DTMPs for Cd reported by Huerta-Diaz and Morse (1992) are less than $10 \%$, presumably because $\mathrm{Cd}^{2+}$ has a much higher water exchange rate than $\mathrm{Fe}^{2+}$ and forms metal sulfides prior to formation of $\mathrm{FeS}$ and $\mathrm{FeS}_{2}$. Otero et al. (2003), however, report a DTMP for Cd of greater than $50 \%$ in the depth interval $19-39 \mathrm{~cm}$ in sediments of the Guaymas Basin. In that case Otero et al. (2003) postulate, "Mn remains immobilized as carbonate, oxyhydroxide or as a metal sulfide, thereby trapping larger amounts of trace metals which are eventually incorporated into the pyrite phase." The Mn concentrations in this study, however, are about 10 times smaller than the concentration of $155 \mu \mathrm{mol} \mathrm{g}$ reported by Otero et al. (2003) at depths of 19$39 \mathrm{~cm}$. Trapping of trace metals by Mn may therefore be less of an issue in Jiaojiang Estuary than the formation with $\mathrm{Fe}$ of mixed sulfides that are insoluble in $\mathrm{HCl}$ (vide supra).

Changes in DOP and DTMP can result from a change in the concentration of metals in either the pyrite (pyrite-Me) or reactive (reactive-Me) fractions, or both. As a check on the implications of the DOP and DTMP depth profiles (Figs. 3, 5), the depth dependence of pyrite-Me concentrations was analyzed for each of the metals examined in this study. Based on analysis of variance, the concentrations of pyrite-Me in the upper $6-8 \mathrm{~cm}$ of sediment were found to be significantly lower $(p<0.03)$ than the concentrations at greater depths for Fe and all metals whose DTMP profiles were judged to be nonrandom by a runs test (Fig. 5). These results are to be expected if physical mixing and bioturbation impact redox conditions in the upper few centimeters of sediment. Consistent with the runs test analyses, ANOVA revealed no significant depth-dependent variations in the pyrite-Me concentrations of $\mathrm{Cd}, \mathrm{Ni}$, and $\mathrm{Zn}$.

A similar ANOVA carried out on reactive metal concentrations revealed that the reactive-Me concentrations of As, $\mathrm{Cd}, \mathrm{Cu}, \mathrm{Hg}$, and $\mathrm{Zn}$ were all higher near the surface of the sediment than at depth $(p \leq 0.0007)$. Remarkably, however, the reactive-Me concentrations of $\mathrm{Cr}, \mathrm{Fe}, \mathrm{Mn}$, and $\mathrm{Pb}$ were all higher at depth than near the surface ( $p \leq 0.04)$. The implication then is that the pyrite-Me concentrations of these four metals increased more rapidly with depth than did their corresponding reactive-Me concentrations, the result being an overall increase in DTMP with depth (Fig. 5). The depth dependence of the reactive$\mathrm{Me}$ concentrations of $\mathrm{Fe}, \mathrm{Cr}, \mathrm{Mn}$, and $\mathrm{Cu}$ is entirely consistent with the depth dependence of their pore water concentrations (Fig. 6). In the first three cases pore water metal concentrations were lower near the surface than at depth; in the latter case the opposite was true. Of the metals examined in this study, both the reactive-Me and pyrite-Me concentrations of only $\mathrm{Ni}$ were independent of depth.

Contrary to expectations of an onshore-offshore gradient in DTMP, in cases where inter-station differences were significant, the lowest DTMPs were observed at station TZ02 in four of six cases (Fig. 4). The most likely explanation for this behavior is the remarkably low AVS concentrations in the upper $20 \mathrm{~cm}$ at station TZ02 (Fig. 2). The cause of these low AVS concentrations is unclear, particularly given the fact that AVS concentrations at depths greater than $28 \mathrm{~cm}$ were virtually identical at stations TZ02 and TZ03 (Fig. 2). To explore the influence of AVS concentrations on DTMPs at station TZ02, the DTMPs of $\mathrm{As}, \mathrm{Cu}, \mathrm{Hg}$, and $\mathrm{Ni}$ were compared (ANOVA) at stations TZ02 and TZ03 at depths between 28 and $38 \mathrm{~cm}$, where AVS concentrations were virtually identical (Fig. 2). No statistically significant differences were found in the DTMPs of these metals within that depth interval. Since these are the four metals whose DTMPs in the upper $30 \mathrm{~cm}$ of sediment were lowest at station TZ02 (Fig. 4), it seems likely that the low AVS concentrations in the upper $20 \mathrm{~cm}$ of sediment were responsible for this result.

The inter-station differences in DOP and DTMP were further explored by using ANOVA to examine the corresponding differences in pyrite-Me and reactive-Me concentrations. There were no significant differences $(p>0.16)$ between stations in the pyrite-Me concentrations of $\mathrm{Cd}, \mathrm{Cr}, \mathrm{Fe}, \mathrm{Mn}$, and $\mathrm{Pb}$. Inter-station differences in pyrite-Me were significant or nearly significant for As $(p=0.02), \quad \mathrm{Hg} \quad(p=0.045), \quad \mathrm{Zn} \quad(p=0.057), \quad \mathrm{Cu}$ $(p=0.071)$, and $\mathrm{Ni}(p=0.075)$. For $\mathrm{Hg}$ and $\mathrm{Ni}$ the lowest pyrite-Me concentrations occurred at station TZ02, and for As and $\mathrm{Cu}$ the highest pyrite-Me concentrations occurred at station TZ01. These results are consistent with the pattern of inter-station differences in DTMP (Fig. 4). Remarkably, inter-station differences in reactive-Me concentrations were significant $(p \leq 0.05$ ) for all metals except $\mathrm{Cu}$. Thus the most consistent cause of inter-station differences in DTMP was differences in reactive-Me and not pyrite-Me concentrations.

\section{Conclusions}

Pyritization of trace metals in the sediments of Jiaojiang Estuary is a function of multiple variables, including AVS concentrations, redox conditions, and pore water metal concentrations. Metal DTMPs that were significantly different between stations were highest in four of six cases at 
station TZ01, where the AVS concentrations were also highest, and were lowest in four of six cases at station TZ02, where the AVS concentrations were lowest. DTMPs were lowest in the upper few centimeters of sediment, as would be expected based on redox conditions. Reactive-Me concentrations varied significantly between stations for all metals except $\mathrm{Cu}$ and in depth profiles were closely correlated with pore water metal concentrations. In most cases DTMPs could be explained on the basis of thermodynamic or kinetic arguments, but in some cases DTMPs were higher than expected based solely on these considerations. Mechanisms such as co-precipitation with pyrite, the existence of complex redox pathways, and the formation with $\mathrm{Fe}$ of mixed sulfides that are insoluble in $\mathrm{HCl}$ are among the likely explanations for the higher than expected DTMPs of some trace metals in these sediments.

Acknowledgments This paper was made possible by the National Natural Science Foundation of China (Grants 40872167) and Key Laboratory of Marine Hydrocarbon Resources and Environmental Geology, Ministry of Land and Resources (MRE200803).

Open Access This article is distributed under the terms of the Creative Commons Attribution Noncommercial License which permits any noncommercial use, distribution, and reproduction in any medium, provided the original author(s) and source are credited.

\section{References}

Berner RA (1970) Sedimentary pyrite formation. Am J Sci 268:1-23 Berner RA (1980) Early diagenesis: a theoretical approach. Princeton University Press, Princeton

Burgess J (1999) Ions in solution: basic principles of chemical interactions, 2nd edn. Horwood, Chichester

Calvert SE, Morris RJ (1977) Geochemical studies of organic-rich sediments from the Namibian Shelf. II. Metal-organic associations. In: Angel MV (ed) A voyage of discovery. Pergamon Press, New York, pp 667-680

Cao W, Wong MH (2007) Current status of coastal zone issues and management in China: a review. Environ Int 33:985-992

Contreras R, Fogg TR, Chasteen ND, Gaudette HE, Lyons WB (1978) Molybdenum in the porewaters of anoxic marine sediments by electron paramagnetic resonance spectroscopy. Mar Chem 6:365-373

Davies-Colley RJ, Nelson PO, Williamson KJ (1985) Sulfide coastal sediment. Biogeochemistry 2:359-376

Edenborn HM, Belzile N, Mucci A, Lebel J, Silverberg N (1986) Observations on the diagnetic behavior of arsenic in a deep coastal sediment. Biogeochemistry 2:359-376

Elderfield H, Hepworth A, Edwards PN, Holliday LM (1979) Zinc in the Conwy River and estuary. Estuar Coast Shelf Sci 9:403-422

Fang T, Zhang X-H, Xu X-Q (2002) Seasonal and vertical distribution of acid volatile sulphide (AVS) in Lake Donghu sediments. Acta Hydrobiol Sin 26:239-245
Fleischer M (1955) Minor elements in some sulfide minerals. Econom Geol 50:970-1024

Framson PE, Leckie JD (1978) Limits of coprecipitation of cadmium and ferrous sulfides. Environ Sci Technol 12:465-469

Hinrichsen D (1999) The coastal population explosion. Trends and future challenges for US National Ocean and coastal policy: proceedings of a workshop, Washington, DC, pp 27-29

Hsieh YP, Shieh YN (1997) Analysis of reduced inorganic sulfur by diffusion methods: improved apparatus and evaluation for sulfur isotopic studies. Chem Geol 137:255-261

Hsieh YP, Chung SW, Tsau YJ, Sue CT (2002) Analysis of sulfides in the presence of ferric minerals by diffusion methods. Chem Geol 182:195-201

Huerta-Diaz MA, Morse JW (1990) A quantitative method for determination of trace metal concentration in sedimentary pyrite. Mar Chem 29:119-144

Huerta-Diaz MA, Morse JW (1992) Pyritization of trace metals in anoxic marine sediments. Geochim Cosmochim Acta 56:26812702

Lord CA (1982) A selective and precise method for pyrite determination in sedimentary materials. J Sediment Petrol 52:664-666

Morse JW (1994) Interaction of trace metals with authigenic sulfide minerals: implications for their bioavailability. Mar Chem 46:16

Morse JW, Luther GW III (1999) Chemical influences on trace metalsulfide interactions in anoxic sediments. Geochim Cosmochim Acta 63:3373-3378

Morse JM, Rickard D (2004) Chemical dynamics of sedimentary acid volatile sulfide. Environ Sci Technol 38:131A-136A

Otero XL, Sánchez JM, Macías F (2000) Bioaccumulation of heavy metals in thionic fluvisols by a marine polychaete: the role of metal sulfide. J Environ Qual 29:1133-1141

Otero XL, Huerta-Diaz MA, Maćias F (2003) Influence of a turbidite deposit on the extent of pyritization of iron, manganese and trace metals in sediments from the Guaymas Basin, Gulf of California (Mexico). Appl Geochem 18:1149-1163

Peterson ML, Carpenter R (1986) Arsenic distribution in porewaters and sediments of Puget Sound, Lake Washington, the Washington coast and Saanich Inlet. Geochim Cosmochim Acta 50:353369

Shea D, Helz GR (1988) The solubility of copper in sulfide waters: sulfide and polysulfide complexes in equilibrium with covellite. Geochim Cosmochim Acta 52:1818-1825

Sokal RR, Rohlf FJ (1981) Biometry, 2nd edn. W. H. Freeman and Company, New York

Westrich JT, Berner RA (1984) The role of sedimentary organic matter in bacterial sulfate reduction: the G model tested. Limnol Oceanogr 29:236-249

Ye S, Wu Q, Zhong S, Zhou Y, Lu J (2006a) Pyritization of trace elements in sediments of the Jiaozhou Bay, Qingdao, China. J China Univers Geosci 31:175-181

Ye S, Zhou Y, Dding X (2006b) Distributions of simultaneously extracted metals (SEM) and its implication for bioavailability in the Jiaojiang estuary of Zhejiang. J Jilin Univers 36:592-598

Zhang X, Zhang L, Wu Y (2003) Study of acid volatile sulfide (AVS) and simultaneously extracted metals (SEM) in clayey tidal zone sediments. J Ocean Univers Qingdao 33:420-424 